\title{
Brief report
}

\section{Prenatal serotonin and neonatal outcome: Brief report}

\author{
Tiffany Field ${ }^{\mathrm{a}, \mathrm{b}, *}$, Miguel Diego ${ }^{\mathrm{a}}$, Maria Hernandez-Reif ${ }^{\mathrm{c}}$, Barbara Figueiredo ${ }^{\mathrm{d}}$, \\ Osvelia Deeds ${ }^{\mathrm{a}}$, Angela Ascencio ${ }^{\mathrm{a}}$, Saul Schanberg ${ }^{\mathrm{e}}$, Cynthia Kuhn ${ }^{\mathrm{e}}$ \\ ${ }^{a}$ Touch Research Institute, University of Miami Medical School, United States \\ ${ }^{\mathrm{b}}$ Fielding Graduate University, United States \\ ${ }^{\mathrm{c}}$ University of Alabama, United States \\ ${ }^{\mathrm{d}}$ University of Minho, Portugal

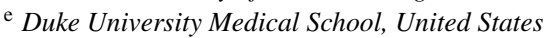

Received 5 July 2007; received in revised form 14 November 2007; accepted 27 December 2007

Keyword: Prenatal serotonin

In a study on prenatal dopamine and its association with depression and other neurotransmitters, serotonin was a confounding variable (Field et al., 2007). Serotonin has long been associated with depression (Cubala \& Landwski, 2006; Neumeister, 2003; Neumeister, Young, \& Stastny, 2004). Serotonin receptors and serotonin transporters are reduced in depression, suggesting that serotonin systems play a key role in the pathophysiology of depression (Neumeister et al., 2004).

Interactions with other systems also occur. Numerous data, for example, have suggested reciprocal interactions between the serotonin system and the hypothalamic-pituitary-adrenal axis (cortisol levels) (Kitamura, Araki, \& Gomita, 2002; McAllister-Williams, Ferrier, \& Young, 1998). Dysfunction in serotonergic and glucocorticoid receptors produces lower mood. Dysfunctional interactions between serotonin and dopamine have also been reported (Esposito, 2006; Kalia, 2005; Trivedi, 2006).

Lower serotonin and dopamine levels and higher cortisol levels have been noted in a recent study on depressed pregnant women (Field, Diego, Dieter, et al., 2004). In that study, this biochemical profile in the prenatally depressed women predicted similar profiles in their neonates (Field, Diego, Hernandez-Reif, Schanberg, \& Kuhn, 2004). The purpose of the present study was to determine the relationships between prenatal serotonin levels and other biochemical values during pregnancy as well as their relationships to neonatal biochemical and behavioral variables. To address that question, the pregnant women were divided into the top and bottom tertiles based on their serotonin levels at 20 weeks gestational age.

\section{Method}

\subsection{Participants}

The participants were 126 depressed pregnant women. The women averaged 25 years of age, their socioeconomic status was low to middle $(M=3.3$ on the Hollingshead index, $R=1-5$ on the Hollingshead Index, with 1 being high

\footnotetext{
* Corresponding author at: Touch Research Institute, University of Miami School of Medicine, PO Box 016820, Miami, FL 33101, United States. Tel.: +1 3052436781 .

E-mail address: tfield@med.miami.edu (T. Field).
} 
SES and 5 being low SES), and they were distributed 55\% Hispanic, 35\% Black and 10\% White, and 30\% were married.

\subsection{Procedure}

The pregnant women were recruited at prenatal clinics at their first ultrasound visit $(M=20$ weeks gestation, $R=16-22$ weeks). Following informed consent, the pregnant women were given the Structured Clinical Interview for DSM-IV Disorders (SCID). Although illicit drug use was an exclusionary criterion, none of the women reported this problem. The women were assessed at 20 weeks and again at 32 weeks gestation, and their infants were evaluated for biochemical and behavioral profiles at the neonatal period $(M=2$ days $)$.

\subsubsection{Structured Clinical Interview for DSM-IV Disorders (SCID)}

All women in the study were given the SCID (research version) to determine depression and anxiety diagnoses and to screen out other disorders including bipolar disorder, schizophrenia and other psychotic disorders. Based on the symptoms identified in the DSM-IV, the women met the criteria for depression. The SCID was administered by research associates following training and with continuing supervision by a clinical psychologist. In our experience (including a recent survey sample), the majority of the depressed pregnant women who attend the university ultrasound clinic were not taking anti-depressants and were not receiving other treatments for depression.

\subsubsection{The Center for Epidemiological Studies-Depression Scale (CES-D)}

This is a 20-item scale that assesses the frequency of depressive symptoms within the last week (Radloff, 1977). With scores ranging from 0 to 60, a cut-off score of 16 is used for classifying a major depressive episode. With only a $6 \%$ false positive and 36\% false negative rate (Myers \& Weissman, 1980), this scale has been shown to be reliable and valid for diverse demographic groups and has been successfully used as a self-report assessment of depression in a number of studies that involved similar populations (e.g., Diego et al., 2004).

\subsubsection{Daily Hassles Scale (Field, Diego, Dieter, et al., 2004)}

This scale was developed to assess the degree of hassle being experienced by expectant mothers. The 16 items on a 4-point Likert scale include questions on family members, landlords, friends and finances creating hassles.

\subsubsection{Urinary catecholamines and metabolites}

Urinary samples were collected from the women at the beginning of the 20 and 32 weeks gestation visits and from the neonates within the first 2 days post-delivery. Assays were conducted by high-pressure liquid chromatography (HPLC) with electrochemical detection (Kilts, Gooch, \& Knopes, 1984). Urinary levels of the dopamine metabolite (HVA) and the serotonin metabolite (5HIAA) were measured, as the majority of excreted catecholamine and serotonin, respectively, exist in the form of these metabolites.

\section{Results}

As can be seen in Table 1 ANOVA and Chi Square comparisons between high $(N=42)$ and low $(N=42)$ serotonin groups based on a tertile split suggested that the high serotonin group women: (1) were greater age, higher socioeconomic status and more often married and (2) had lower CES-D depression, CES-D somatic-vegetative subscale and Daily Hassle Scale scores. As can be seen in Table 2, the high serotonin versus low serotonin level group had: (1) higher serotonin and dopamine levels at the 20 weeks gestation period and (2) higher serotonin and dopamine levels at the 32 weeks gestation period. As can be seen in Table 3, the neonates of the mothers in the high serotonin versus low serotonin level group had higher serotonin levels themselves, and most importantly, they were less likely to be born prematurely ( $10 \%$ vs. $\left.20 \%, X^{2}=5.02, p=.05\right)$.

\section{Discussion}

These data on pregnant women are consistent with previous data on non-pregnant adults, suggesting that depression scores were higher in those with low serotonin levels (Neumeister et al., 2004). Both the CES-D summary 
Table 1

Means for background and self-report variables for pregnant women divided into top and bottom (high and low) tertiles on prenatal serotonin (5HIAA) levels (S.D.s in parentheses)

\begin{tabular}{|c|c|c|c|c|c|}
\hline Background variables & Low serotonin & High serotonin & $X^{2}$ & $F$ & $p$ \\
\hline Age & $26.0(6.1)$ & $29.7(5.7)$ & & 15.40 & .000 \\
\hline Socioeconomic status & $3.5(1.3)$ & $2.8(1.2)$ & & 12.70 & .000 \\
\hline Marital status (\%) & 22.4 & 42.4 & 7.9 & & .05 \\
\hline \multicolumn{6}{|l|}{ Self-report variables } \\
\hline CES-D depression & $23.4(12.0)$ & $16.5(9.4)$ & & 5.60 & .02 \\
\hline CES-D somatic-vegetative & $9.03(4.0)$ & $6.63(2.9)$ & & 5.20 & .03 \\
\hline Daily Hassles & $25.7(6.3)$ & $22.5(7.2)$ & & 4.10 & .05 \\
\hline
\end{tabular}

Table 2

Means for biochemical values for pregnant women divided into top and bottom (high and low) tertiles on prenatal serotonin (5HIAA) levels (S.D.s in parentheses)

\begin{tabular}{lcrr}
\hline & Groups & & $F$ \\
\cline { 2 - 3 } & Low serotonin & High serotonin & \\
\hline Biochemical values (20 weeks GA) & & & \\
Serotonin (5HIAA) & $2159.4(651.7)$ & $6590.5(1876.6)$ & 388.10 \\
Dopamine (HVA) & $240.4(125.9)$ & $331.7(141.7)$ & 18.10 \\
Norepinephrine (NE) & $58.5(26.4)$ & $57.8(24.9)$ & .000 \\
Cortisol (CO) & $206.6(103.1)$ & $250.4(130.8)$ & NS \\
Biochemical values (32 weeks GA) & & & NS \\
Serotonin (5HIAA) & $2917.3(2000.3)$ & $4765.9(1939.8)$ & .000 \\
Dopamine (HVA) & $225.1(131.1)$ & $283.8(145.2)$ & .05 \\
Norepinephrine (NE) & $47.0(24.9)$ & $55.6(23.7)$ & 4.01 \\
Cortisol (CO) & $246.6(138.2)$ & $321.5(148.8)$ & NS \\
\hline
\end{tabular}

scores and the somatic-vegetative symptom subscale scores were higher for the low serotonin level pregnant women.

The simultaneously elevated serotonin and dopamine across pregnancy ( 20 and 32 weeks gestation) in this sample are consistent with an interactive phenomenon suggested by others (Esposito, 2006; Trivedi, 2006). One system appears to affect the other, confounding the effects of each system (Trivedi, 2006). Serotonin notably confounded the dopamine effects in a tertile split on dopamine levels in pregnant women (Field et al., 2007). Although the literature would also suggest negative relations between serotonin and cortisol levels (Kitamura et al., 2002; McAllister-Williams et al., 1998), cortisol levels surprisingly did not differ between the high and low serotonin groups in this sample.

The neonates of the high serotonin mothers had similarly higher serotonin levels than the neonates of low serotonin mothers. We have noted parallel biochemical profiles of pregnant women and their neonates in at least 3 samples (Field et al., 2004b; Field et al., 2007; Lundy, Field, Cigales, Cuadra, \& Pickens, 1999).

Table 3

Means for biochemical values for neonates of pregnant women divided into top and bottom (high and low) tertiles on prenatal serotonin (5HIAA) levels (S.D.s in parentheses)

\begin{tabular}{lcrr}
\hline & Groups & & $F$ \\
\cline { 2 - 3 } & Low serotonin & High serotonin & \\
\hline Neonatal biochemical values & & & \\
Serotonin (5HIAA) & $4853.9(3663.3)$ & $8204.8(4215.8)$ & 4.71 \\
Dopamine (HVA) & $412.8(290.2)$ & $422.1(245.6)$ & .05 \\
Norepinephrine (NE) & $60.4(34.1)$ & $79.2(38.2)$ & NS \\
Cortisol (CO) & $560.1(237.3)$ & $507.2(200.5)$ & NS \\
\hline
\end{tabular}


The reciprocal relationships often noted between serotonin and dopamine and serotonin and cortisol were surprisingly not evident for the neonates in this sample. That the incidence of prematurity in the low serotonin group was twice the rate in the high serotonin group suggests that low serotonin levels, like elevated cortisol, may be a marker for preterm delivery (Field, Diego, Hernandez-Reif, et al., 2004). These data highlight the importance of monitoring serotonin levels during prenatal assessments. Urine samples collected at prenatal clinics could be assayed for serotonin, dopamine and cortisol levels, as they may help identify women at risk for premature delivery. In addition, the CES-D scores and especially the somatic-vegetative subscale scores on the CES-D, appear to be elevated in women with low prenatal serotonin levels.

These measures may be cost-effective screening assessments for targeting those women needing prenatal interventions, especially since they seem to have some predictive validity as early as 20 weeks gestation which may not be too late for intervention. Various forms of stimulation have been noted to at least lower prenatal depression and cortisol including yoga and massage therapy (Field, Diego, Hernandez-Reif, et al., 2004; Narendran, Nagarathna, Narendran, Gunasheela, \& Nagendra, 2005) and to increase serotonin and dopamine including massage therapy (Field, Hernandez-Reif, Diego, Schanberg, \& Kuhn, 2005) and exercise (Strüder et al., 1997). Thus, with these cost-effective screening measures and interventions, the costly problems of prematurity may be reduced. Future studies would need to be conducted on larger samples to assess the validity of these screening measures.

\section{Acknowledgments}

We would like to thank the mothers and infants who participated in this study. This research was supported by a Merit Award (MH\# 46586) and NIH grant (AT\# 00370) and Senior Research Scientist Awards (MH\# 00331 and AT\# 001585) and a March of Dimes Grant (\# 12-FYO3-48) to Tiffany Field and funding from Johnson and Johnson Pediatric Institute to the Touch Research Institute.

\section{References}

Cubala, W., \& Landwski, J. (2006). Serotoninergic system and limbic-hypothalamic-pituitary-adrenal axis (LHPA axis) in depression. Psychiatry Polska, 40, 415-430.

Diego, M., Field, T., Hernandez-Reif, M., Cullen, C., Schanberg, S., \& Kuhn, C. (2004). Prepartum, postpartum and chronic depression effects on newborns. Psychiatry, 67, 63-80.

Esposito, E. (2006). Serotonin-dopamine interaction as a focus of novel antidepressant drugs. Current Drug Targets, 7, $177-185$.

Field, T., Diego, M., Dieter, J., Hernandez-Reif, M., Schanberg, S., Kuhn, C., et al. (2004). Prenatal depression effects on the fetus and the newborn. Infant Behavior \& Development, 27, 216-229.

Field, T., Diego, M., Hernandez-Reif, M., Figueiredo, B., Deeds, O., Ascencio, A., Schanberg, S. \& Kuhn, C. (2007). Prenatal Dopamine and Neonatal Behavior and Biochemistry. (In Review).

Field, T., Diego, M., Hernandez-Reif, M., Schanberg, S., \& Kuhn, C. (2004). Massage therapy effects on depressed pregnant women. Journal of Psychosomatic Obstetrics and Gynaecology, 25, 155-222.

Field, T., Hernandez-Reif, M., Diego, M., Schanberg, S., \& Kuhn, C. (2005). Cortisol decreases and serotonin and dopamine increase following massage therapy. International Journal of Neuroscience, 115, 1397-1413.

Kalia, M. (2005). Neurobiological basis of depression: An update. Metabolism, 54, 24-27.

Kilts, C., Gooch, M., \& Knopes, K. (1984). Journal of Neuroscience and Methods, 11, 257-273.

Kitamura, Y., Araki, H., \& Gomita, Y. (2002). Interaction of 5HT and HPA axis in depression and treatment-resistant depression. Nippo Yakurigaku Zasshi, 119, 319-325.

Lundy, B. L., Jones, N. A., Field, T., Nearing, G., Davalos, M., Pietro, P., Schanberg, S., \& Kuhn, C. (1999). Prepartum depression effects on neonates. Infant Behavior and Development, 22, 121-137.

McAllister-Williams, R., Ferrier, I., \& Young, A. (1998). Mood and neuropsychological function in depression: The role of corticosteroids and serotonin. Psychological Medicine, 28, 537-584.

Myers, J., \& Weissman, M. (1980). Use of a self-report symptom scale to detect depression in a community sample. American Journal of Psychiatry, 137, 1081-1084.

Narendran, S., Nagarathna, R., Narendran, V., Gunasheela, S., \& Nagendra, H. R. (2005). Efficacy of yoga on pregnancy outcome. Journal of Alternative Complementary Medicine, 11, 237-244.

Neumeister, A. (2003). Tryptophan depletion, serotonin, and depression: Where do we stand? Psychopharmacology, 37, 99-115.

Neumeister, A., Young, T., \& Stastny, J. (2004). Implications of genetic research on the role of serotonin type 1A receptor and the serotonin transporter. Psychopharmacology, 174, 512-524.

Radloff, L. (1977). The CES-D Scale: A self-report depression scale for research in the general population. Applied Psychology Measures, 3, $385-401$. 
Strüder, H. K., Hollmann, W., Platen, P., Wöstmann, R., Ferrauti, A., \& Weber, K. (1997). Effect of exercise intensity on free tryptophan to branched-chain amoni acids ratio and plasma prolactin during endurance exercise. Canadian Journal of Applied Psychology, 22, 280291.

Trivedi, M. (2006). Major depressive disorder: Remission of associated symptoms. Journal of Clinical Psychiatry, 67, 27-32. 